\title{
Simplified Reliability Estimation for Optimum Strengthening Ratio of 30-Year-Old Double T-Beam Railway Bridge by NSM Techniques
}

\author{
Minkwan Ju, ${ }^{1}$ Hongseob Oh, ${ }^{2}$ and Jong-Wan Sun ${ }^{3}$ \\ ${ }^{1}$ Department of Civil Engineering, Kangwon National University, 1 Joonang-ro, Kangwon, Samcheok 245-711, Republic of Korea \\ ${ }^{2}$ Department of Civil Engineering, Gyeongnam National University of Science and Technology, 150 Chilam-dong, Jinju, Gyeongnam \\ 660-758, Republic of Korea \\ ${ }^{3}$ Research Division, G3Way Co., Yangjae-dong, Seocho, Seoul 20-32, Republic of Korea
}

Correspondence should be addressed to Hongseob Oh; opera69@chol.com

Received 25 November 2013; Revised 3 March 2014; Accepted 4 March 2014; Published 11 May 2014

Academic Editor: Ting-Hua Yi

Copyright (C) 2014 Minkwan Ju et al. This is an open access article distributed under the Creative Commons Attribution License, which permits unrestricted use, distribution, and reproduction in any medium, provided the original work is properly cited.

\begin{abstract}
This study is to develop simplified reliability estimation for optimum strengthening ratio of T-beam railway bridge strengthened by CFRP strip. Until now, strengthening design has been usually proceeded to satisfy the target load-carrying capacity by using the deterministic parameter of nominal property for concrete or FRP. For the optimum strengthening design, however, it is required that reliability-based strengthening design should be applied to effectively determine the amount of strengthening material and make sure of the safety of the structure. As applying the reliability-based strengthening ratio, more reliable strengthening design using CFRP strip is possible as well as having a structural redundancy. The reliability-based strengthening design methodology suggested in this study is able to contribute the optimum strengthening design for a concrete structure strengthened by CFRP strip.
\end{abstract}

\section{Introduction}

FHWA 2009 [1] reported that many existing reinforced concrete bridges, especially superstructures, have consistently experienced deteriorations with significant loss of loadcarrying capacity. As the national budget is decreased for the new construction, the repair and strengthening needs have been major consideration in maintenance field of infrastructure. In the last decade, the conventional strengthening materials have been replaced with fiber reinforced polymer (FRP) materials for strengthening of the deteriorated concrete structures. Among these FRP strengthening material forms, FRP laminate and sheet are widely applied on the surface of the structure to be strengthened by the externally bonded reinforcing (EBR) technique. For this strengthening, however, the previous researches have raised several kinds of problems that the EBR technique cannot sufficiently transfer tensile strength of the FRP materials to concrete member, due to their premature debonding [2]. Near surface mounted (NSM) strengthening technique has many advantages for improving the structural capacity over a conventional ERB strengthening: less site installation work, better bonding and structural performance, and more effective maintenance point of view. For these reasons, many experimental researches have suggested that NSM-FRP strengthening is one of the most reliable strengthening techniques for concrete structures [3-5]. Although EBR technique needs additional external protection against either the fire attack or an unexpected collision the NSM strengthening technique provides better protection in disaster situations than conventional EBR [6] methods.

Also NSM using FRP strips has substantially better bond resistance because it can be embedded in an adhesive entirely within the narrow groove of the substrate concrete. This advantage of FRP strips for bonding performance was previously demonstrated by Soliman et al. [7]. In a monotonic load test, the NSM CFRP strip demonstrated better anchorage than the EBR CFRP strips $[8,9]$.

Although many studies for FRP strengthening have been conducted previously, there are few studies to suggest 

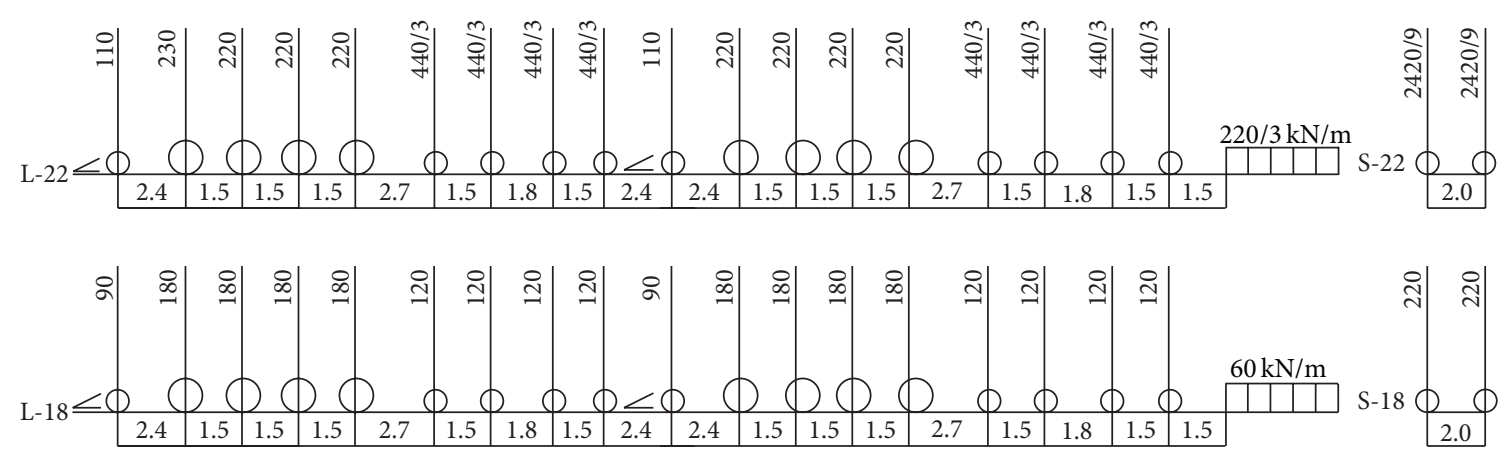

Wheel load $(\mathrm{kN})$

Length (m)

FIgURE 1: Standard train load in Korea (LS-18, LS-22).

the strengthening guideline, such as a strengthening ratio, by applying a probabilistic and reliability analysis. This is important because of the uncertainty for material and structural point of view on the FRP strengthening method. A parametric study of GFRP rebar for design factors such as cross-sectional dimension, GFRP, and concrete strength [10] is conducted. Another research is carried out a reliability assessment of an FRP-strengthened concrete beam by Chinese codes [11]. A parametric study on the effects of influencing factors on average reliability level shows that load effect ratio and concrete strength are the first two dominant influencing factors among all design variables. For design concepts, the conventional ultimate strength design (USD) method is changed to limit state design after 2015 in Korea. Therefore, safety and reliability for all structures will be regarded widely, as well as the strengthening of concrete structures.

This study aims to propose the reliability-based determination procedure on the strengthening ratio of a deteriorated concrete girder with CFRP strips, which has advantages for the full composite performance with concrete members. The target bridge in this study is a double T-beam railway bridge originally designed by LS-18 (an old type of design load for a railway bridge in Korea). Therefore, it is required that the target bridge should satisfy the present design load (LS-22) and enhance the design speed, with the high speed era in the future. In order to assess the optimal strengthening ratio for the target bridge in this study, the CFRP strip strengthening method was analytically applied to the target bridge.

NSM strengthening technique is more effective for enhancing flexural capacity of railway bridge in case vibration of train traffic due to its superior bond performance. The goal of this study was to calculate the reliability-based strengthening ratio of the concrete beams strengthened by NSM using CFRP strips by applying the reliability index for bridge design. FE analysis, on the deteriorated and then strengthened bridge, was performed using the design railway load in the Korea railway specification. FEM analysis was also used to estimate the amount of steel reinforcements of the target bridge, due to the absence of structural design information of this aged bridge. To consider the structural uncertainties of the strengthening method, the probability and reliability analysis were performed with Monte Carlo simulation (MCS). Finally, the reliability-based strengthening ratio which satisfies the reliability index for the structural design $(\beta=3.5)$ is estimated with the structural redundancy for the target design strength. Finally, it is suggested that the strengthening procedure of the applied probabilistic and reliability approach is a reasonable strengthening design method.

\section{Estimation of the Unknown Property of Target Bridge}

The target bridge is a simply supported railway bridge in Korea, which was built for the design load of LS-18 in 1982. In Design Specification of Railway of Korea [15], standard design load is categorized as LS-18 restricted to $120 \mathrm{~km} / \mathrm{hr}$ and LS-22 for high speed railway, as depicted in Figure 1. Actual speed and dynamic behavior on the LS-18 train were monitored and analyzed by [16].

Figures 2 and 3 show the typical cross-section and longitudinal view of the RC T bridge.

There are some recent diagnosis techniques [17-19]. For this bridge, conventional inspection method was applied. Some of deterioration defects, such as cracks, efflorescence, steel corrosion, and concrete segregation, were visualized by inspection. Whereas the compressive strength of concrete is $40.8 \mathrm{MPa}$, the strength of steel rebar is not verified from the field inspection.

To evaluate the requirement of strengthening amount, a load-carrying capacity or flexural stiffness for the structural condition in service mode should be investigated. Due to the characteristics of this railway bridge, dynamic tests for structural evaluation were performed using in-field monitoring data for the train loads passing the target point [16], with structural stiffness as the main indicator of structural condition. For this, acceleration data was monitored and compared with an RC bridge with a similar span length and size. According to Hwang et al. [16], the acceleration of the target bridge was shown to be over $0.4 \mathrm{~g}\left(1 \mathrm{~g}\right.$ is $980 \mathrm{~cm} / \mathrm{s}^{2}$, gal) 


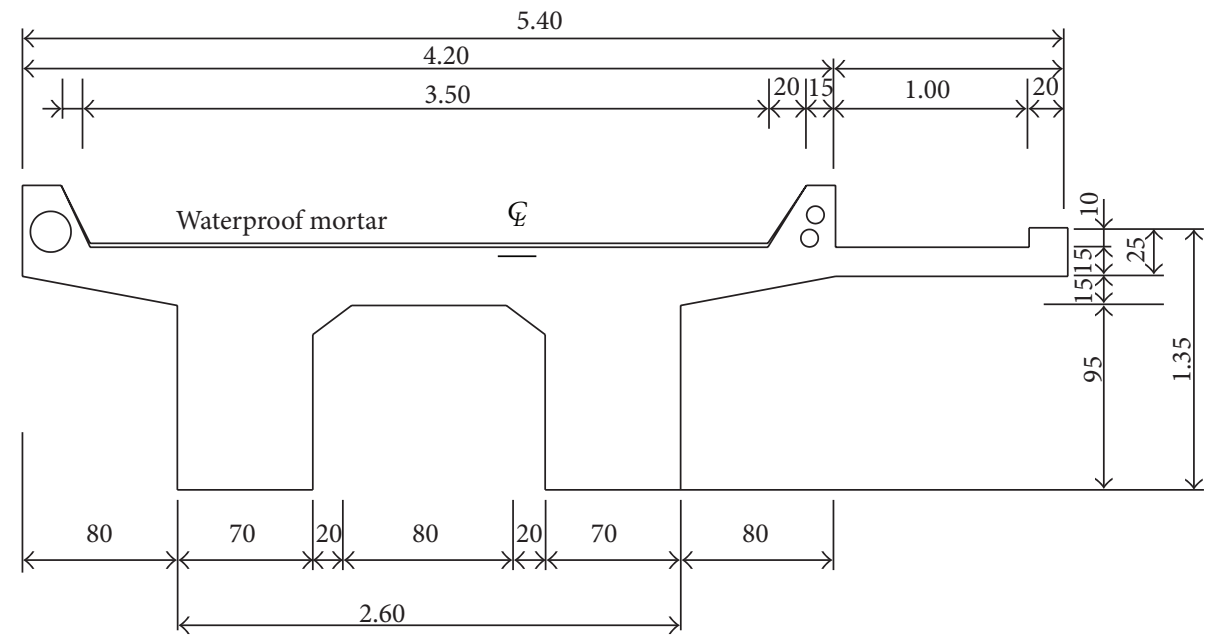

FIgURE 2: A cross-section of the target bridge (unit: m).

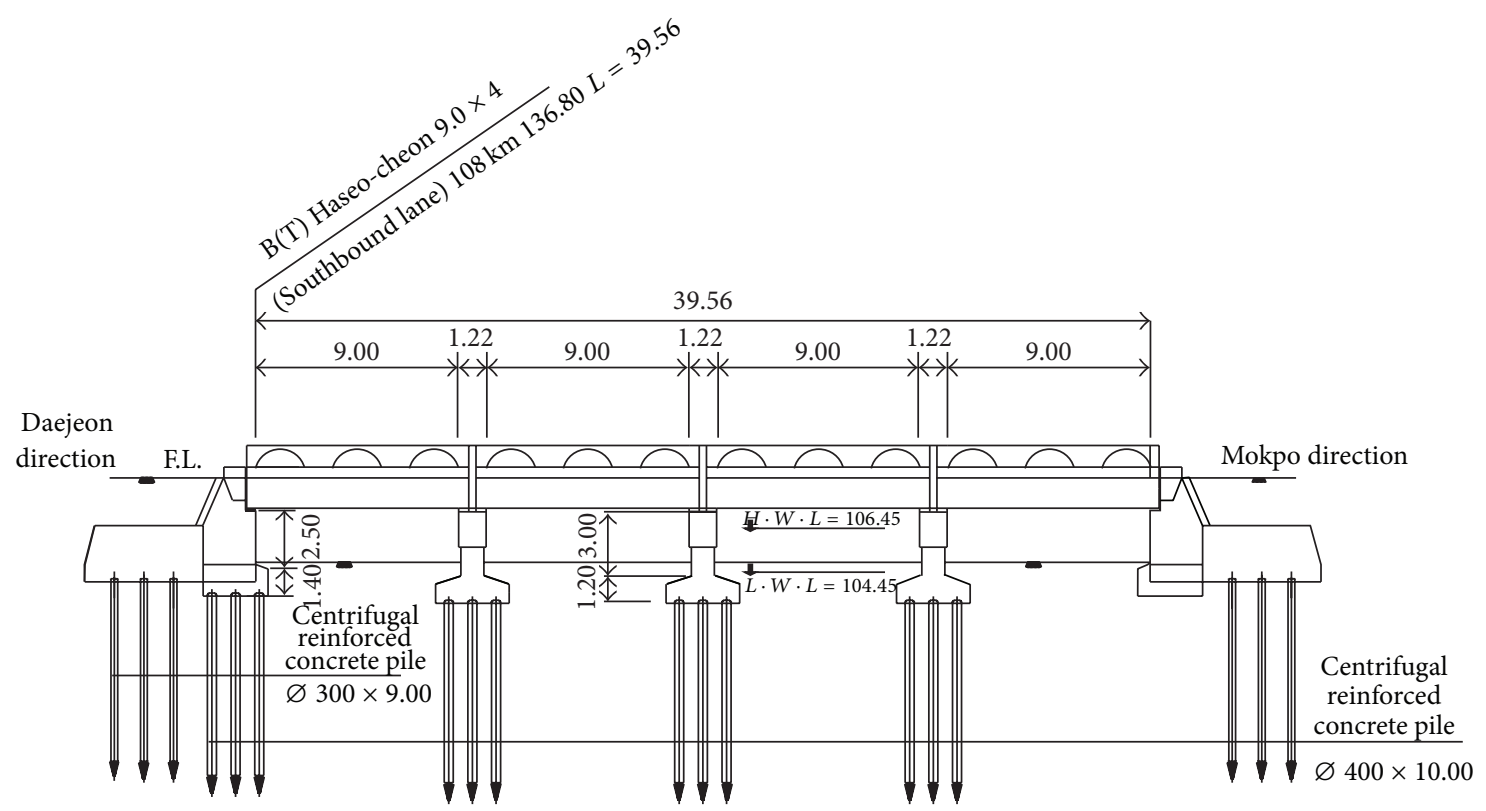

FIgURE 3: A longitudinal view of the target bridge.

when the train passed. In Europe, it is recommended that the acceleration should be under $0.35 \mathrm{~g}$ for the prevention of turbulence on the railway in service $[20,21]$. Thus, highlevel acceleration in service is considered proof of structural performance degradation and the appropriate strengthening means to satisfy the serviceability limit are required. To solve the vibration problem, strengthening by FRP composite can enhance the structural stiffness [22, 23]. For another strengthening need, structural condition was recorded as C-grade after an in-depth inspection conducted in 2003 [24]. During the bridge's 30 years of service time, structural materials such as concrete and steel reinforcement have possibly deteriorated. Therefore, the target bridge should be treated with structural upgrade maintenance. In this study, FRP strip strengthening of the deteriorated target bridge is an effective strategy, and the strengthening ratio-the most significant factor for the strengthening design-will be suggested through a reliability analysis of material and structural uncertainties using a reliability index.

To assess the amount of adequate strengthening ratio to satisfy the requirement, the unknown reinforcement ratio of steel rebar should be reasonably estimated. Structural analysis on the target bridge without the steel rebar was initially performed to calculate external flexural moment subjected by LS-18 design loads. The structural modeling and analysis were conducted by commercial FEA program [25]. The bridge model was built by plate and solid elements, the dead load like gravel, rail was excepted. Figure 4 shows the analysis results of external flexural moments for dead and live loads. The design load factors for dead and live loads were based on the 


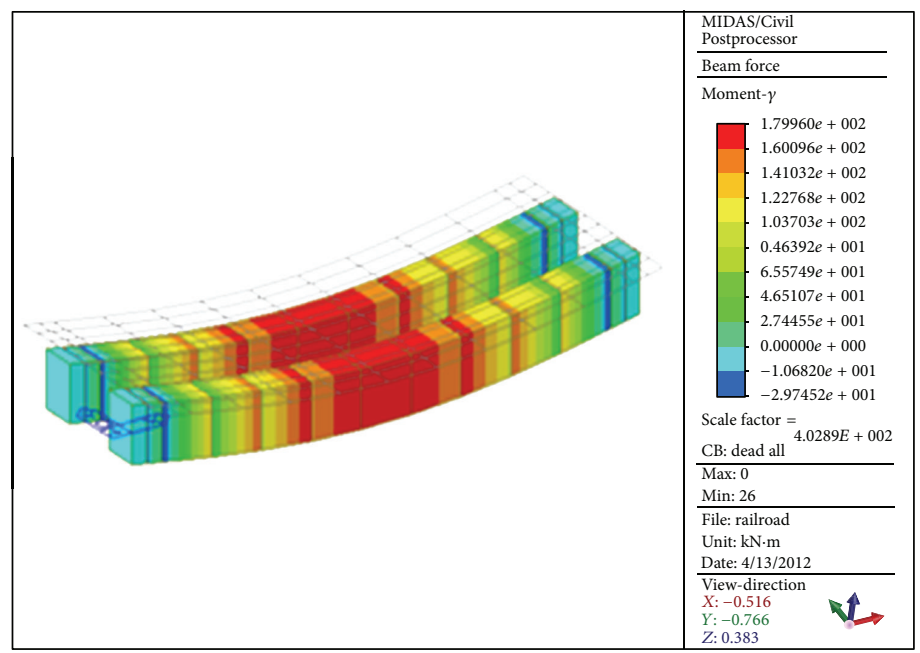

(a) Bending moment diagram for a factored dead load

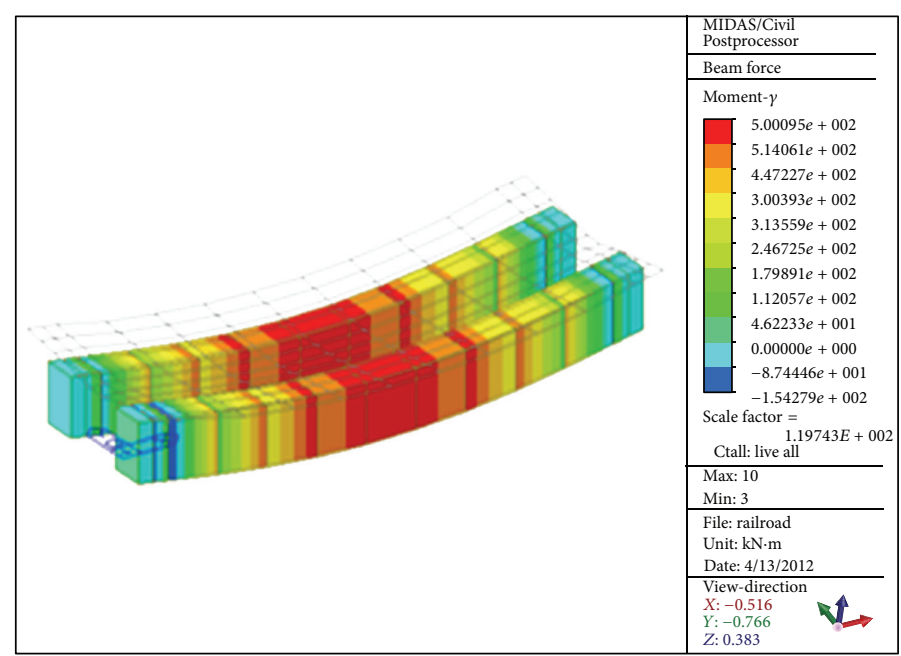

(b) Bending moment diagram for a factored live load

Figure 4: FE analyses for dead and live loads.

design specification of railway of Korea and were 1.4 and 2.0, respectively.

The design flexural moment by FE analysis was calculated as $761.0 \mathrm{kN} \cdot \mathrm{m}$. With this moment capacity, the area of steel rebar can be estimated as $1,718 \mathrm{~mm}^{2}$ by the moment equilibrium equation for the rectangular beam with an effective width of slab.

\section{Limit State Function and Safety Index}

3.1. Limit State Function. The conventional performance function for flexural capacity of the bridge cross-section consists of $R, D$, and $L$, where $R$ is strength resistance or load carrying capacity, $D$ is dead load effect, and $L$ is live load effect including impact [26]. For consideration of the limit state, the limit state model to express railway by Cho et al. [27] was adapted and followed as

$$
g(\cdot)=R-\left(S_{D}+S_{L}\right)
$$

where $R$ is structural resistance and $S_{D}$ and $S_{L}$ are dead and live load effect, respectively. $R, S_{D}$, and $S_{L}$ are reexpressed as follows:

$$
\begin{gathered}
R=R_{n} \cdot D_{F} \cdot N_{R} \\
S_{D}=C_{D} \cdot D_{n} \cdot N_{D} \\
S_{L}=C_{L} \cdot L_{n} \cdot K_{S}(1+i) \cdot N_{L},
\end{gathered}
$$

where $R_{n}$ is estimated nominal strength of undamaged structures (flexural moment or shear force), $D_{F}$ is damage coefficient, $N_{R}$ is uncertain parameter when $R_{N}$ and $D_{F}$ are estimated, $C_{D}$ and $C_{L}$ are the effect factor of flexural moment and shear force for dead and live loads, $D_{n}$ and $L_{n}$ are the nominal dead and live loads, respectively, $K_{S}$ is the response ratio (Calculation/Measure), $i$ is the impact factor, and $N_{D}$ and $N_{L}$ are the calibration factors of $C_{D}$ and $C_{L}$, respectively. $N_{R}$ can be calculated by P.M.F.D: P for uncertainties of estimation for analytical model, $\mathrm{M}$ for material strength, $\mathrm{F}$ for fabrication, and D for damage factors. In this study, structural 


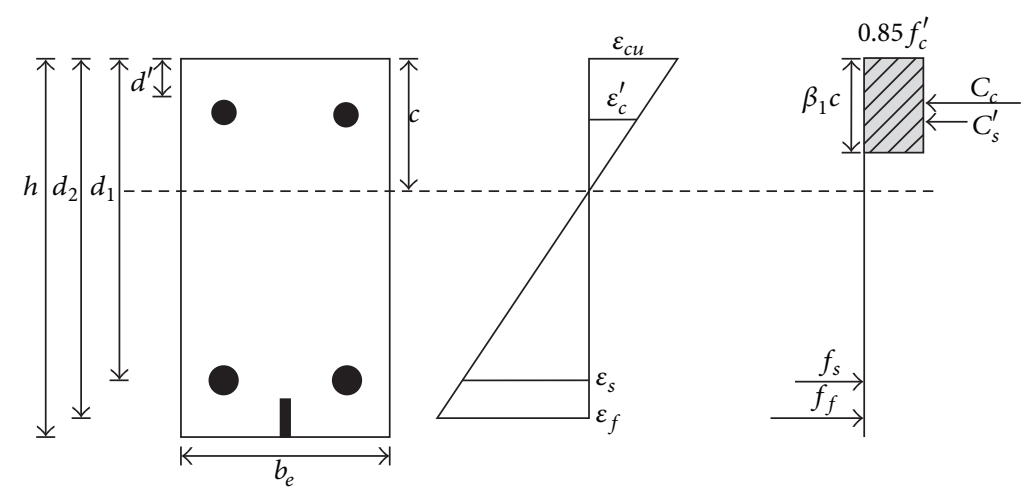

FIGURE 5: Compatibility diagram of strain and strength of the cross-section for strengthening.

failure denotes the state when the theoretical flexural capacity is reached. Failure occurs if the function $g$ is less than or equal to zero.

As depicted in Figure 5, the resistance moment $\left(M_{n}\right)$ used in this reliability analysis is calculated by (3) to (6) according to the recommendations from ACI Committee 440 [28] and Bank [29]. In this study, the damage factor $D_{f}$ was newly applied in the steel rebar terms in (5):

$$
\begin{gathered}
C_{1}+C_{2}=T_{1}+T_{2} \\
0.85 f_{c}^{\prime} \beta_{1} b_{e} c+A_{s}^{\prime} f_{s}^{\prime}=A_{s} f_{s}+A_{f} f_{f} \\
M_{n}=D_{f} A_{s}\left(d_{1}-\frac{\beta_{1} c}{2}\right)+\psi_{\mathrm{frb}} A_{f} f_{f}\left(H-\frac{\beta_{1} c}{2}\right) \\
M_{u} \geq \Phi M_{n},
\end{gathered}
$$

where $A_{s}$ is area of tensile steel bar $\left(\mathrm{mm}^{2}\right), f_{s}$ is tensile stress of steel bar $(400 \mathrm{MPa}), h$ is total height $(1,250 \mathrm{~mm})$, $d_{1}$ is effective depth of tensile steel bar $(1,200 \mathrm{~mm}), d_{2}$ is effective depth of CFRP strip $(1,220 \mathrm{~mm}), d^{\prime}$ is effective depth of compressive steel bar $(50 \mathrm{~mm}), A_{f}$ is area of CFRP strip $\left(\mathrm{mm}^{2}\right), f_{f}$ is effective strength of CFRP strip $\left(f_{\mathrm{fu}, \mathrm{ave}}-3 \sigma\right.$, $\mathrm{MPa}), \psi_{\text {frp }}$ is environmental reduction factor $(0.85), \Phi$ is strength reduction factor $(0.85), f_{c}^{\prime}$ is compressive strength of concrete $(41 \mathrm{MPa})$, and $b_{e}$ is effective width of rectangular beam $(1,900 \mathrm{~mm}) . D_{f}$ means the damage factor assumed in the reliability analysis (Table 4 ).

In the case of failure mode of a concrete beam externally bonded with CFRP materials, except in a premature failure case, the following four failure modes are classified representatively:

(1) steel yielding and concrete compressive failure before CFRP rupture;

(2) steel yielding and CFRP rupture after concrete compressive failure;

(3) CFRP rupture and concrete compressive failure before steel yielding;

(4) concrete compressive failure before steel yielding and CFRP rupture.
Among the Cases 1 4, Cases 3 and 4 are typical overstrengthening failure, which leads to brittle failure of strengthening beams. Cases 1 and 2, however, would result in ductile failure, rather than that of Cases 3 and 4. For reasonable failure cases, Case 1) is more suitable for preventing the brittle failure because concrete compressive failure is less brittle than that of CFRP strip. Balanced failure means that a strengthened concrete member fails simultaneously with concrete compressive failure and CFRP rupture.

Structural safety can be conveniently calculated with respect to the reliability index $\beta$ as follows:

$$
\beta=\frac{\mu_{g}}{\sigma_{g}} .
$$

The variables $\mu_{g}$ and $\sigma_{g}$ are the terms of the mean and standard deviation of the performance function $g$, respectively. The reliability index for flexural capacity after strengthening is calculated based on the effective cross-section of the target bridge with the amount of CFRP strip required to satisfy the strength for NSM strengthening. In this study, the reliability index is computed by the Rackwitz-Fiessler algorithm [30].

3.2. Computational Uncertainty Factors $\left(K_{s}\right)$. The computational uncertainties, $K_{s}$, are adapted to be considered in predicting resistance. The statistics for randomness are defined based on analytical results or test results. Some analytical and test results are introduced by a literature review of previous research papers for reliability analysis [10]. In this study, it is assumed that statistics of the computational uncertainty factor in concrete crushing mode are effective to estimate the strengthening ratio by reliability analysis. Thus, from data from a total of 91 specimens, 1.061 of mean value and 0.09 of standard deviation resulted. The following equation denotes the computational uncertainties in this analysis:

$$
K_{s}=\frac{M_{U, \exp }}{M_{U, \text { pre }}} .
$$

3.3. Damage Factor. Cho et al. [31] have theoretically defined that the damage factor is the ratio of stiffness for a nondamaged structure to a damaged structure. For quantitative 


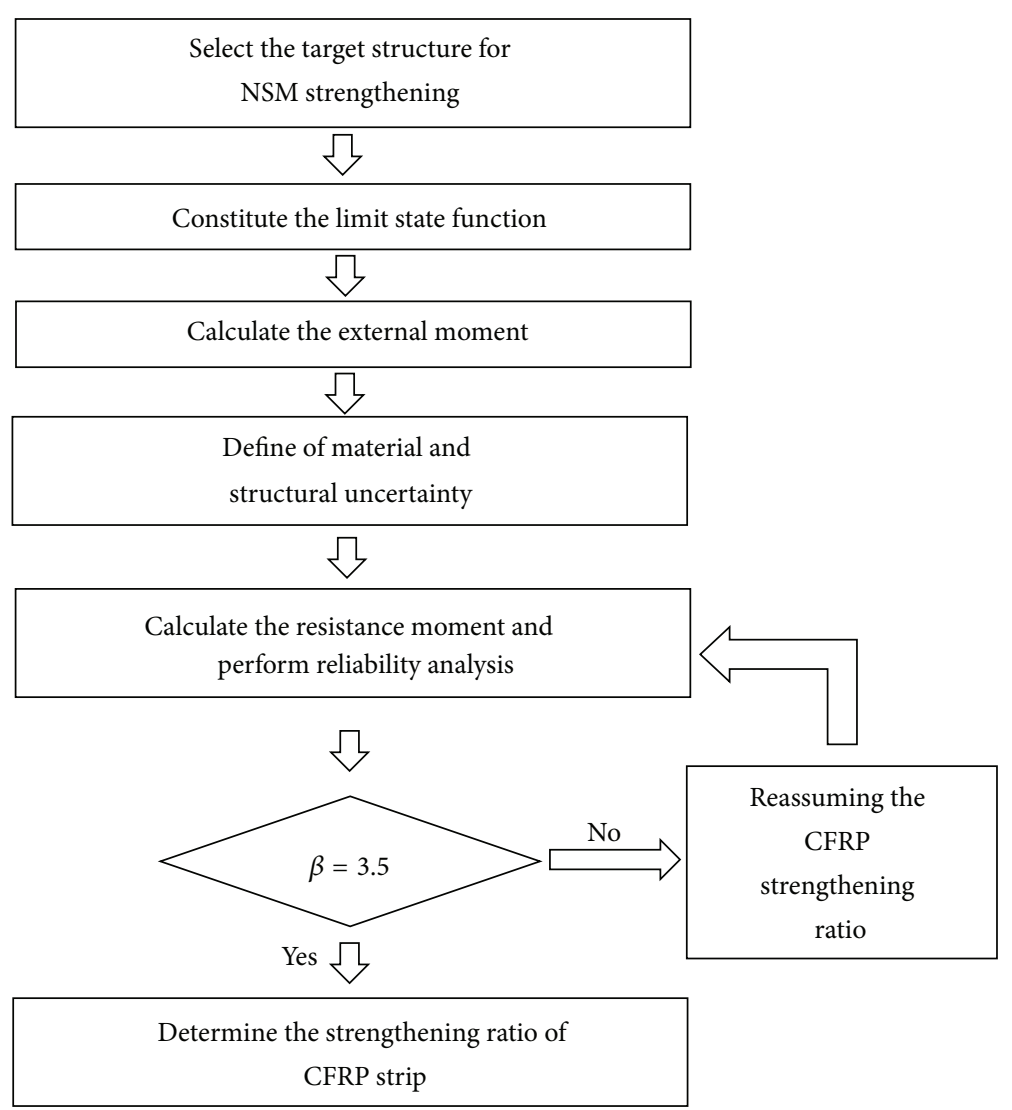

FIGURE 6: A procedure for determining the reliability-based strengthening ratio of CFRP strip with a target reliability index of 3.5.

approaches, it can be calculated by using the ratio of power of natural frequency for a damaged structure to that for a nondamaged structure. In actual state, however, it is not asserted that this ratio can directly represent the degree of damage. Estimating the damage factor is hard to be determined without the plentiful history data so that the damage factor in this study is assumed by previous research [29]. Therefore, the average of damage factor is ranged from 0.6 to 0.9 and uncertainty of damage factor is considered from 0.1 to 0.3 of coefficient of variation. With this statistical data, the probability and reliability analysis are carried out and a result of sensitive analysis for the variation of damage factor is discussed.

\section{Characteristics of Random Variables}

For reliability analyses, the statistics of random variables are defined in advance. There are three variables considered in this analysis: external load for dead and live ones, material strength of concrete, steel rebar and CFRP strip, and design of cross-section.

In the reliability analysis for structural safety, it is essential that the load effect must be considered by combining the variability of loads, dead and live loads. A related study was conducted and suggested the load and resistance factors for $\mathrm{RC}$ concrete design [32]. Table 1 shows the statistics of the load effect for dead and live load for reliability analysis [33]. Among these, mean value is the external moment resulting from FE analysis to the target bridge, and load factor is based on the KR specification.

The statistics of resistance-related variables such as $f_{c}^{\prime}, h$, and $d$ listed in Table 2 are adopted from Ellingwood [32]. Also included in Table 2 are the statistics of the strength of CFRP strip $\left(f_{\mathrm{fu}}\right)$ for Barros and Fortes [34] and of the width (b) of T-beam for Oh et al. [13]. In the case of the nominal value of $h$ and $d$, the real dimension of the cross section in the target bridge is used. For steel rebar, statistics from many of tensile tests are summarized in Table 3 [35]. As compared with Grade series by ASTM A 165, SD30, SD35, and SD40 rebar considered in the reliability analysis showed relatively better coefficient of variation. The probability distribution was considered as normal type. In this study, statistics of SD40 in Korea were adopted in reliability analysis.

\section{Reliability-Based Strengthening Ratio of CFRP Strip}

5.1. Target Safety Index in Reliability Analysis. This study is to calculate the reliability-based strengthening ratio of CFRP strip to the existing railway bridge, which has structural uncertainties. Therefore, it is important to define how much structural safety should be acquired. This is simply determined by using the reliability index, or the target safety factor, $\beta$, in the load and resistance analysis. Previous study has shown that $\beta$ values of 2.5 3.0 and 3.0 3.5 were used 
TABLE 1: Result of FEM analysis for external railway load.

\begin{tabular}{lccccr}
\hline & Probability distribution & Mean/Nominal & Mean & COV $^{\mathrm{a}}$ & Load factor \\
\hline Dead load & Normal & 1.05 & $180.0 \mathrm{kN} \cdot \mathrm{m}$ & 0.1 & 1.4 \\
Live load & Lognormal & 1.00 & $580.8 \mathrm{kN} \cdot \mathrm{m}$ & $0.2-0.4$ & 2.0 \\
\hline
\end{tabular}

${ }^{\mathrm{a} C O V}$ : coefficient of variation.

TABLE 2: Statistics of random design variables (I).

\begin{tabular}{lcccc}
\hline Design variable & Nominal value & Mean value & Standard deviation & Probability distribution \\
\hline$f_{c}^{\prime}(\mathrm{MPa})$ & 41.34 & 46.16 & 1.94 & Normal \\
$f_{\mathrm{fu}}(\mathrm{MPa})^{\mathrm{a}}$ & - & 2,790 & 85.7 & Normal \\
$b(\mathrm{~mm})^{\mathrm{b}}$ & 1,900 & $b+0.94$ & 6.0 & Normal \\
$h(\mathrm{~mm})^{\mathrm{c}}$ & 1,250 & $h-3.05$ & 6.35 & Normal \\
$d(\mathrm{~mm})^{\mathrm{c}}$ & 1,200 & $d-4.70$ & 12.70 & Normal \\
\hline
\end{tabular}

${ }^{\mathrm{a}}$ ISO 527-3 (1997)[12], ${ }^{\mathrm{b}}$ Oh et al. (1993) [13], ${ }^{\mathrm{c}}$ cross-sectional dimension of the target bridge.

TABLE 3: Statistics of random design variables (II).

\begin{tabular}{lcccccc}
\hline & Mean/Nominal & COV & Average strength & Number of data & Standard deviation & Probability distribution \\
\hline SD 30 & 1.20 & 0.064 & 360.0 & 822 & 23.04 & Normal \\
SD 35 & 1.13 & 0.038 & 395.5 & 40 & 773.03 & Normal \\
SD 40 & 1.09 & 0.048 & 436.0 & - & 20.93 & Normal \\
Grade $40^{\mathrm{b}}$ & 1.13 & 0.116 & 317.0 & - & 36.72 & Normal \\
Grade $60^{\mathrm{b}}$ & 1.12 & 0.098 & 472.5 & & 46.31 & Normal \\
\hline
\end{tabular}

${ }^{\mathrm{a}}$ KS D 3504.

bASTM A 615: Standard Specification for Deformed and Plain Carbon Steel Bars for Concrete Reinforcement-AASHTO No.: M 31 [14].

for tension failure and compression failure, respectively [36]. Kulicki et al. [37] proposed the target, or code-specified reliability indices obtained from reliability analysis of a group of 175 existing actual bridges designed by either ASD or LFD method, and then suggested the range of values using the new load and resistance factors. From this research, AASHTO altered the reliability index to 3.5 when either a higher level of safety or taking more risk was appropriate [38]. According to the recent research [39], the target beta for beam is 3.5 for flexural strength of RC beams constructed with light weight and normal weight concrete. In this study, the target reliability index is determined with 3.5 and a reliability-based strengthening ratio satisfying the probability index $\beta=3.5$ will be calculated.

5.2. Result of Reliability Analysis. To evaluate the reliabilitybased strengthening ratio of the target bridge, the probability distribution between the external load and structural resistance from the limit state function was analyzed. A safety margin was used and $\beta_{T}=3.5$ of target reliability index was specified by AASHTO [38]. Figure 6 is a process to calculate strengthening ratio of CFRP strip by reliability analysis with a reliability index of 3.5. FEM analysis should be conducted to determine the external moment for dead and live loads. Structural resistance is affected as when strengthening ratio of CFRP strip is varied. Therefore, iteration process is needed until safety margin of 3.5 of the strengthening bridge against external load is acquired.

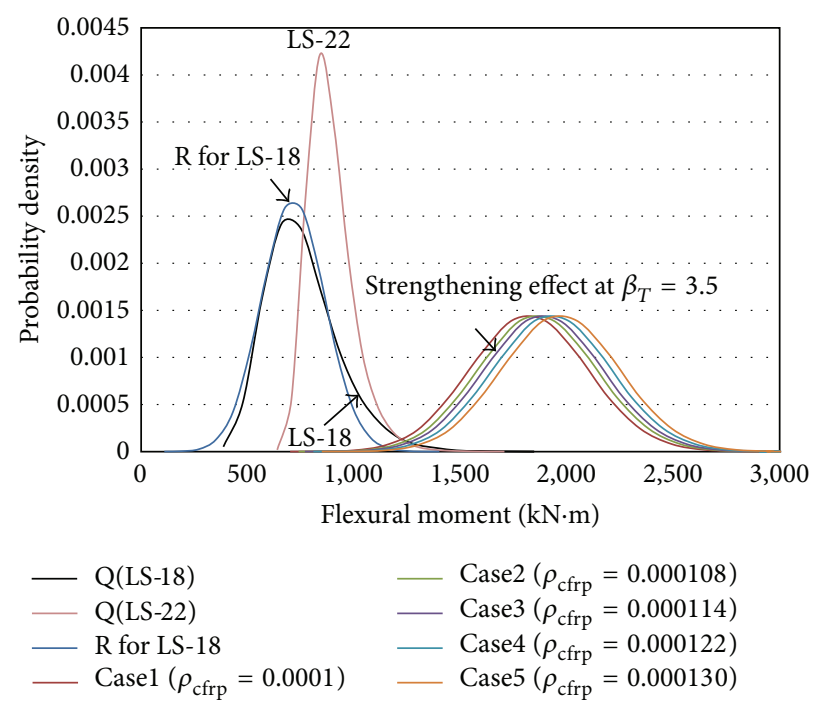

Figure 7: Probability distribution curves for external load and resistance.

Figure 7 is the probability distribution curves for external load and resistance resulted from the reliability analysis. For external loads, the probability distribution of LS-22 was additionally considered to investigate the how much the strengthening effect of CFRP strips can decrease the probability of failure compared LS-22 design load. Q means the external load and $R$ is for the resistance moment. 
TABLE 4: Sensitive analysis for damage factor, standard deviation of damage factor, and live load effect.

\begin{tabular}{|c|c|c|c|c|c|c|c|}
\hline & Damage factor & Standard deviation & $\mathrm{COV}$ & $\rho_{\mathrm{CFRP}}$ at $\beta_{T}=3.5$ & Live load moment & Standard deviation & $\mathrm{COV}$ \\
\hline Case 1 & 0.7 & 0.14 & 0.2 & 0.000128 & 290.4 & 87.12 & 0.3 \\
\hline Case 2 & 0.8 & 0.16 & 0.2 & 0.000114 & 290.4 & 87.12 & 0.3 \\
\hline Case 3 & 0.9 & 0.18 & 0.2 & 0.000102 & 290.4 & 87.12 & 0.3 \\
\hline Case 4 & 0.8 & 0.08 & 0.1 & 0.000048 & 290.4 & 87.12 & 0.3 \\
\hline Case 5 & 0.8 & 0.16 & 0.2 & 0.000114 & 290.4 & 87.12 & 0.3 \\
\hline Case 6 & 0.8 & 0.24 & 0.3 & 0.000196 & 290.4 & 87.12 & 0.3 \\
\hline Case 7 & 0.8 & 0.16 & 0.2 & 0.000095 & 290.4 & 58.08 & 0.2 \\
\hline Case 8 & 0.8 & 0.16 & 0.2 & 0.000114 & 290.4 & 87.12 & 0.3 \\
\hline Case 9 & 0.8 & 0.16 & 0.2 & 0.000137 & 290.4 & 116.16 & 0.4 \\
\hline
\end{tabular}

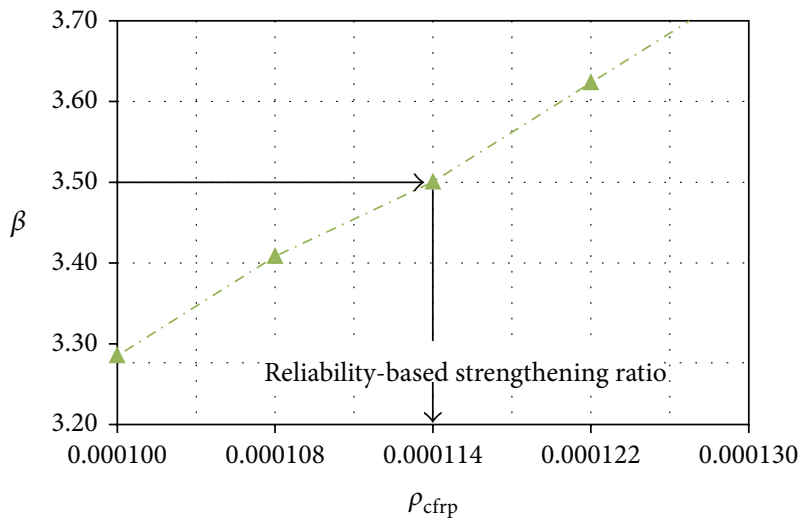

FIGURE 8: Critical strengthening ratio of CFRP strip strengthened by NSM.

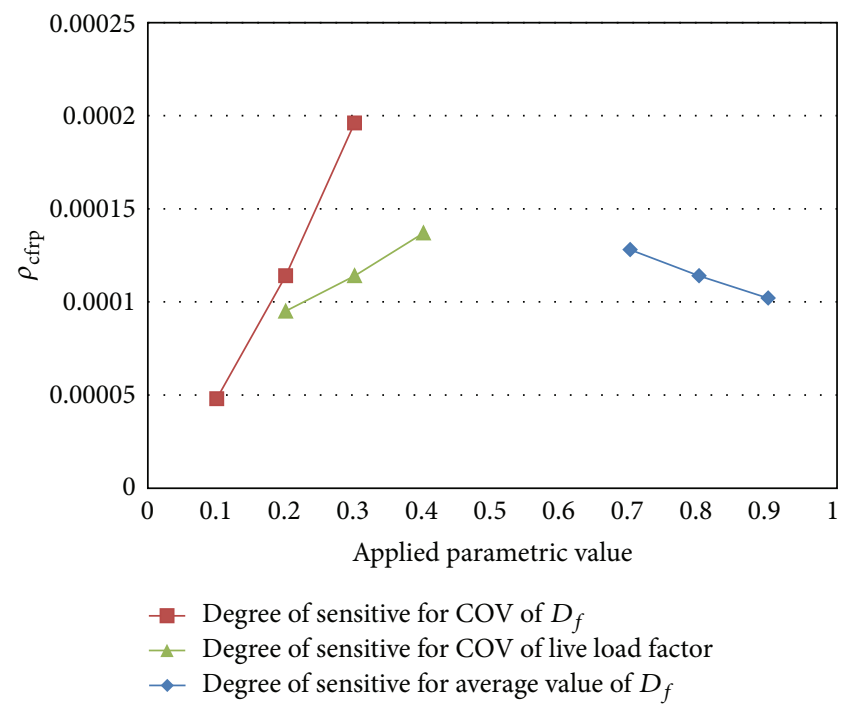

FIGURE 9: Sensitive analysis for COV and average value of $D_{f}$ and COV of live load factor.

Strengthening effect is denoted as a case series. FEM analysis was performed to calculate the external moment for LS-18 and LS-22 design railway load. For probability distribution of LS-22, which is the present design load of railway in Korea, probability characteristics for LS-18 were used in the same way. In order to acquire the reliability-based strengthening ratio for $\beta_{T}=3.5$, the range of probability parameters was roughly considered; then the final 5 cases for $\rho_{\text {cfrp }}$ from 0.0001 to 0.00013 were analyzed. Each probability distribution curve is illustrated in Figure 7. Figure 8 is the result of reliabilitybased strengthening ratio. According to the result of the strengthening effect by probability distribution, the target bridge strengthened by the CFRP strip strengthening ratio resulting from the reliability analysis could be sufficiently safe against the LS-22 present design railway load. As the strengthening ratio of CFRP strip that could satisfy $\beta_{T}=3.5$, it was with $\rho_{\text {cfrp }}=0.000114$.

5.3. Sensitive Analysis for Three Important Parameters. Figure 9 shows the result of sensitive analysis for three parameters such as damage factor, standard deviation of damage factor, and live load effect. The CFRP strip strengthening ratio resulting from the reliability analysis is plotted with three important parameters. The purpose of this process is to identify how sensitively the strengthening ratio will be affected when the three parameters are varied independently. The determination of the variation ranges of the parameters was considered to simply but effectively apply the sensitive characteristics. For live loads and damage factor, there were similar degrees of sensitivity. Variation of COV of damage factor, however, was more sensitive than that of the other parameters. It might be concluded that $\mathrm{COV}$ of damage factor largely affected to estimate the reliability-based strengthening using about the CFRP strip. For more reliable estimation of damage factor, many of structural diagnosis data should be analyzed in future. Table 4 summarizes the input parameters used in the sensitive analysis.

\section{Conclusions}

This study suggested the reliability-based strengthening ratio for 30-year-old railway bridge using CFRP strips. Conclusions are as follows.

(1) In previous strengthening schemes, it has been uncertain to determine how much the strengthening effect should be required. The methodology for the reliability-based strengthening ratio can improve 
these problems of the previous strengthening method. The target reliability index for CFRP strip strengthening is considered as 3.5 according to AASHTO specification. As using the reliability-based strengthening ratio in this study, more effective strengthening design to concrete structure, having a specified strengthening target as well as reflecting the structural and material uncertainties, is possible.

(2) In the result of a sensitive analysis, variation of COV for damage factor mostly affected to the reliabilitybased strengthening ratio of CFRP strip. Therefore, damage factor should be studied more properly on the target bridge. This may be possible by analyzing the database for long-term safety inspection history and its reasonable quantification. Stabilization and normalization processes of the damage factor are also required.

(3) One of the important factors for determining the safety margin against the resistance is external load effect. In order to improve the reliability-based strengthening ratio of CFRP strip in this study, uncertainties for external load of a railway bridge should be analytically and experimentally verified. This can be solved by analyzing the acquired data from long-term monitoring; then the reliability of the strengthening ratio of CFRP strip will be promoted.

\section{Conflict of Interests}

The authors declare that there is no conflict of interests regarding the publication of this paper.

\section{Acknowledgments}

This work was supported by Korea Institute of Energy Technology Evaluation and Planning (0000000015513) and Research grant from Gyeongnam National University of Science and Technology.

\section{References}

[1] FHWA Bridge Programs NBI data, 2009, http://www.fhwa.dot .gov/bridge/nbi.

[2] ACI Committee 440, Guide for the Design and Construction of Externally Bonded FRP Systems for Strengthening Concrete Structures (ACI 440.2R-08), American Concrete Institute, Farmington Hills, Mich, USA, 2008.

[3] J. M. de Sena Cruz and J. A. O. De Barros, "Bond between nearsurface mounted carbon-fiber-reinforced polymer laminate strips and concrete," Journal of Composites for Construction, vol. 8, no. 6, pp. 519-527, 2004.

[4] T. Hassan and S. Rizkalla, "Investigation of bond in concrete structures strengthened with near surface mounted carbon fiber reinforced polymer strips," Journal of Composites for Construction, vol. 7, no. 3, pp. 248-257, 2003.

[5] S. M. Soliman, E. El-Salakawy, and B. Benmokrane, "Flexural behavior of concrete beams strengthened with near surface mounted FRP bars," in Proceedings of 4th International conference on FRP composites in civil engineering (CICE '08), 2008.
[6] J. P. Firmo, J. R. Correia, and P. França, "Fire behaviour of reinforced concrete beams strengthened with CFRP laminates: protection systems with insulation of the anchorage zones," Composites Part B: Engineering, vol. 43, no. 3, pp. 1545-1556, 2012.

[7] S. M. Soliman, E. El-Salakawy, and B. Benmokrane, "Bond performance of near-surface-mounted FRP bars," Journal of Composites for Construction, vol. 15, no. 1, pp. 103-111, 2011.

[8] T. Hassan and S. Rizkalla, "Flexural strengthening of prestressed bridge slabs with FRP systems," PCI Journal, vol. 47, no. 1, pp. 76-93, 2002.

[9] J. R. Yost, S. P. Gross, and D. W. Dinehart, "Near surface mounted CFRP reinforcement for structural retrofit of concrete flexural members," in Proceedings of the 4th International Conference on Advanced Composite Materials in Bridges and Structures, Calgary, Canada, 2004.

[10] Z. He and F. Qiu, "Probabilistic assessment on flexural capacity of GFRP-reinforced concrete beams designed by guideline ACI 440.1R-06," Construction and Building Materials, vol. 25, no. 4, pp. 1663-1670, 2011.

[11] Z. He and L. Jiang, "Flexural reliability assessment of FRPstrengthened reinforced concrete beams designed by Chinese CECS-146 Guideline," Pacific Science Review, vol. 9, no. 1, pp. 123-133, 2007.

[12] International Organization for Standardization, "Determination of tensile properties-part 5: test conditions for unidirectional fibre reinforced plastic composites," ISO 527-5, International Organization for Standardization, Geneva, Switzerland, 1997.

[13] B. H. Oh, C. K. Koh, S. W. Baik, H. J. Lee, and S. H. Han, "Realistic reliability analysis of reinforced concrete structures," Journal of Korea Society of Civil Engineering, vol. 13, no. 2, pp. 121-133, 1993 (Korean).

[14] Steel bars for concrete reinforcement, KS D 3504, Korean Industrial Standards, 2011 (Korean).

[15] KR Network, Design Specification of Railway: Railway Bridge, Korea Rail Network Authority, Seoul, Republic of Korea, 2004, (Korean).

[16] S. K. Hwang, J. T. Oh, J. S. Lee et al., Performance Enhancement of Railway System-Track \& Civil: Development of the Design Specification for Improving Dynamic Characteristics of Railway Bridges, Korea Railway Research Institute, Seoul, Republic of Korea, 2003, (Korean).

[17] H. S. Shang, T. H. Yi, and L. S. Yang, "Experimental study on the compressive strength of big mobility concrete with nondestructive testing method," Advances in Materials Science and Engineering, vol. 2012, Article ID 345214, 6 pages, 2012.

[18] T. H. Yi, H. N. Li, and H. M. Sun, "Multi-stage structural damage diagnosis method based on "energy-damage" theory," Smart Structures And Systems, vol. 12, no. 3-4, pp. 345-361, 2013.

[19] H. S. Shang, T. H. Yi, and X. X. Guo, "Study on strength and ultrasonic of air-entrained concrete and plain concrete in cold environment," Advances in Materials Science and Engineering, vol. 2014, Article ID 706986, 7 pages, 2014.

[20] Korea High Speed Rail Construction Authority (KHRC), "Bridge design manual (BRDM)," Technical Report, Korea High Speed Rail Construction Authority (KHRC), Pusan, Public of Korea, 1995, (Korean).

[21] International Union of Railway, UIC Code 776-1R: Loads to Be Considered in Railway Bridge Design, International Union of Railway, Paris, France, 4th edition, 1994. 
[22] M. Abdessemed, S. Kenai, A. Bali, and A. Kibboua, "Dynamic analysis of a bridge repaired by CFRP: experimental and numerical modelling," Construction and Building Materials, vol. 25, no. 3, pp. 1270-1276, 2011.

[23] G. Zanardo, H. Hao, Y. Xia, and A. J. Deeks, "Stiffness assessment through modal analysis of an RC slab bridge before and after strengthening," Journal of Bridge Engineering, vol. 11, no. 5, pp. 590-601, 2006.

[24] Korea Infrastructure Safety and Technology corporation (KISTEC), A Database of Maintenance History, Korea Infrastructure Safety and Technology corporation (KISTEC), Gyeonggi-do, Republic of Korea, 2003, (Korean).

[25] MIDAS IT, MIDAS Civil Program Manual, MIDAS IT, Gyeonggi, Republic of Korea, 2009.

[26] S. W. Tabsh and A. S. Nowak, "Reliability of highway girder bridges," Journal of Structural Engineering ASCE, vol. 117, no. 8, pp. 2372-2388, 1991.

[27] H. N. Cho, K. H. Kwak, and S. J. Lee, "Reliability-based safety and capacity evaluation of high-speed railway bridges," Journal of Computational Structural Engineering Institute in Korea, COSEIK, vol. 10, no. 3, pp. 133-143, 1997 (Korean).

[28] ACI Committee 440, Guide for the Design and Construction of Externally Bonded FRP Systems for Strengthening Concrete Structures, American Concrete Institute, Farmington Hills, Mich, USA, 2008.

[29] L. C. Bank, Composites for Construction-Structural Design with FRP Materials, John Wiley \& Sons, New York, NY, USA, 2006.

[30] R. Rackwitz and B. Flessler, "Structural reliability under combined random load sequences," Computers and Structures, vol. 9, no. 5, pp. 489-494, 1978.

[31] H. N. Cho, H. H. Choi, S. Y. Lee, and J. W. Sun, "Methodology for reliability-based assessment of capacity-rating of plate girder railway bridges using ambient measurement data," Journal of Korea Society of Steel Construction, vol. 15, no. 2, pp. 187-196, 2003 (Korean).

[32] B. Ellingwood, Reliability Bases of Load and Resistance Factors for Reinforced Concrete Design, National Bureau of Standards Building Science Series 110, Washington, DC, USA, 1978.

[33] US Department of Commrece/National Bureau of Standards, "Development of a probability based load criteria for American National Standard A58," NBS Special Publication 577, U.S. Department of Commrece/National Bureau of Standards, Gaithersburg, Md, USA, 1980.

[34] J. A. O. Barros and A. S. Fortes, "Flexural strengthening of concrete beams with CFRP laminates bonded into slits," Cement and Concrete Composites, vol. 27, no. 4, pp. 471-480, 2005.

[35] S. H. Kim, H. K. Cho, H. W. Bae, and H. S. Park, "Reliability evaluation of structures-a case of reinforced concrete buildings under dead, live, and wind loads," Technical Report, Korea Institute of Construction Technology, 1989, (Korean).

[36] J. G. MacGregor, "Load and resistance factors for concrete design," Journal of the American Concrete Institute, vol. 80, no. 4, pp. 279-287, 1983.

[37] J. M. Kulicki, D. R. Mertz, and W. G. Wassef, "LRFD Design of highway bridges," NHI Course 13061, Federal Highway Administration, Washington, DC, USA, 1994.

[38] AASHTO, Bridge Design Practice, American Association of State Highway and Transportation Officials, Washington, DC, USA, 2011.

[39] A. S. Nowak and A. M. Rakoczy, "Reliability-based calibration of design code for concrete structures (ACI 318)," in Proceeding of the Anais do 54 Congress Brasileiro do Concreto CBC201254CBC, pp. 1-12, 2012. 


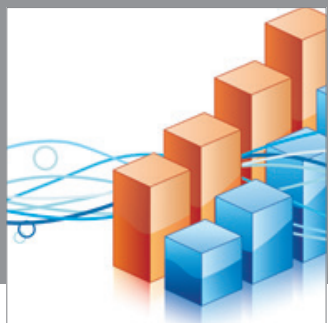

Advances in

Operations Research

mansans

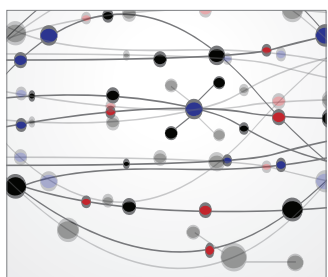

The Scientific World Journal
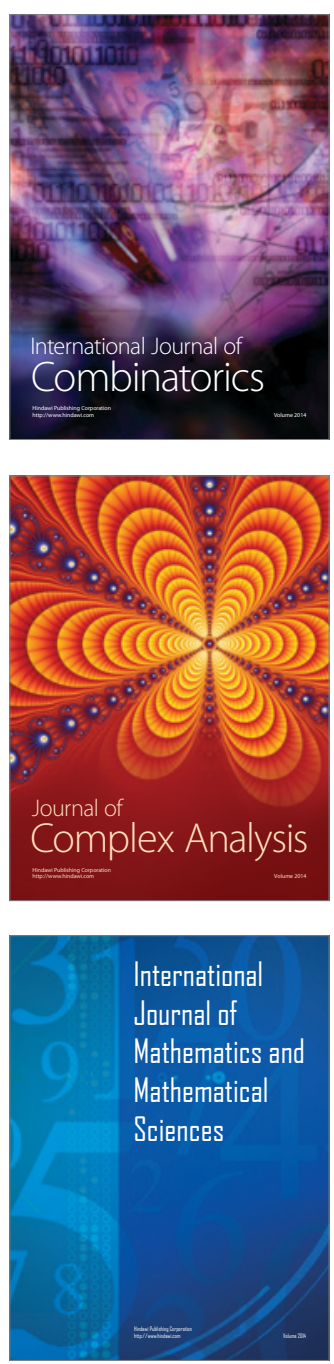
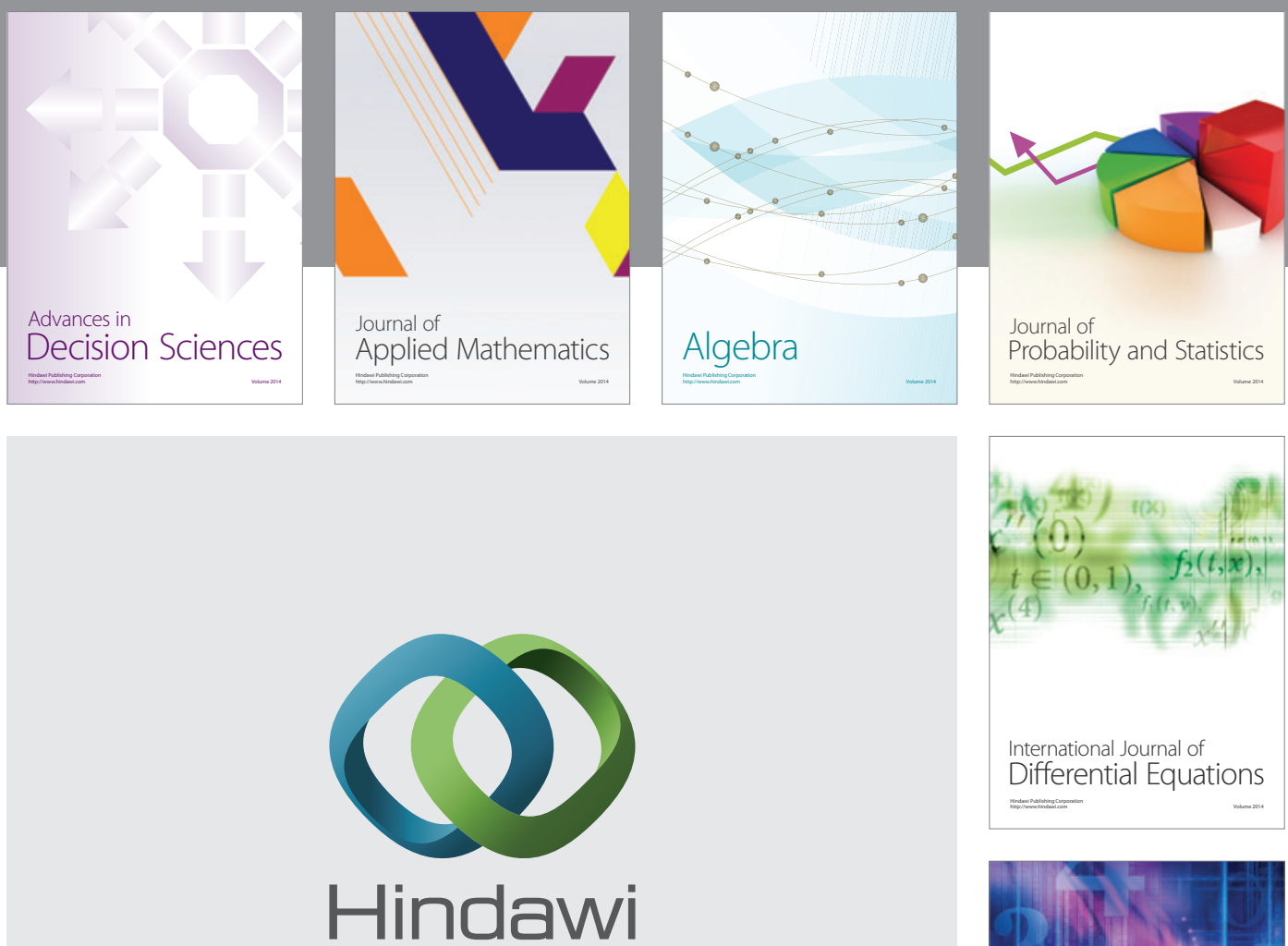

Submit your manuscripts at http://www.hindawi.com
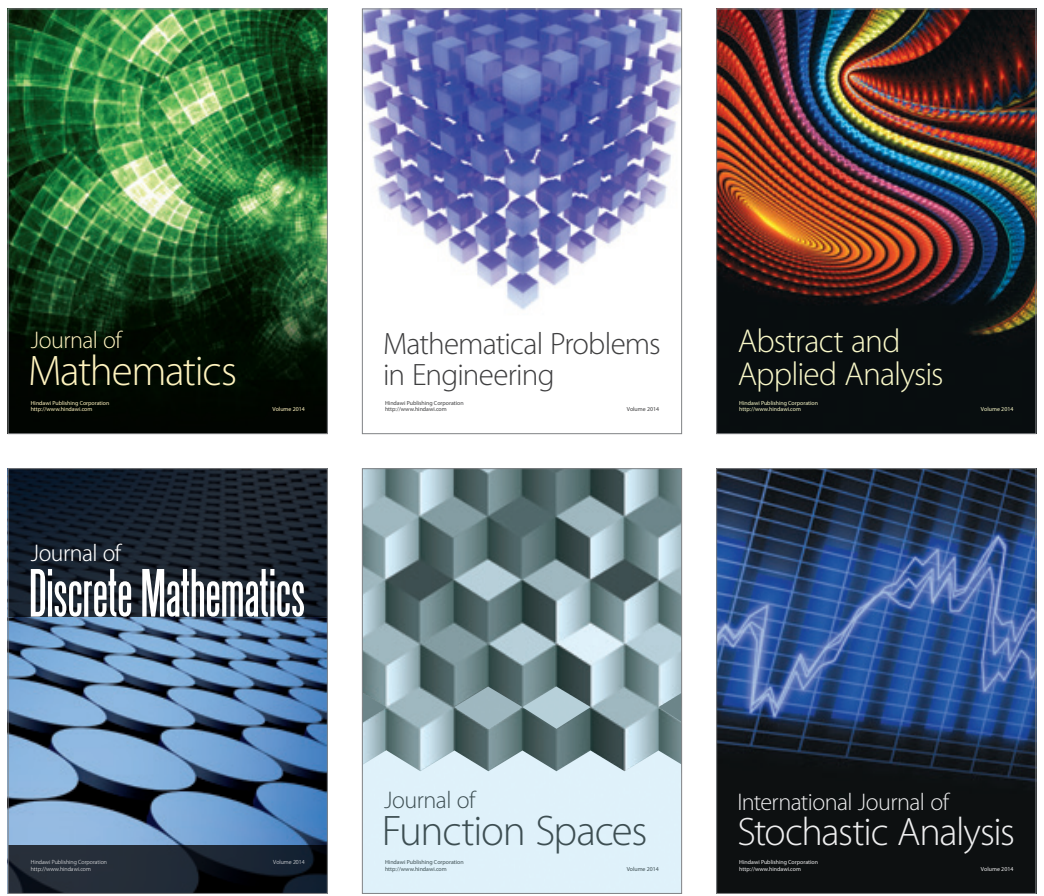

Journal of

Function Spaces

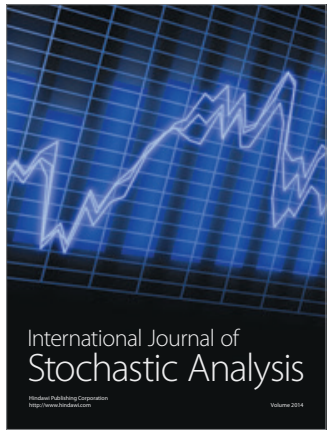

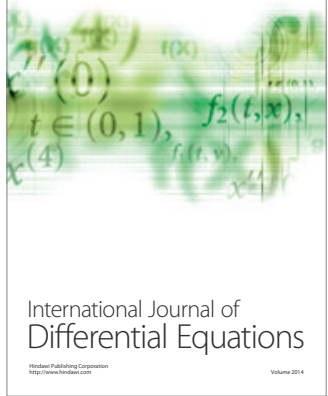
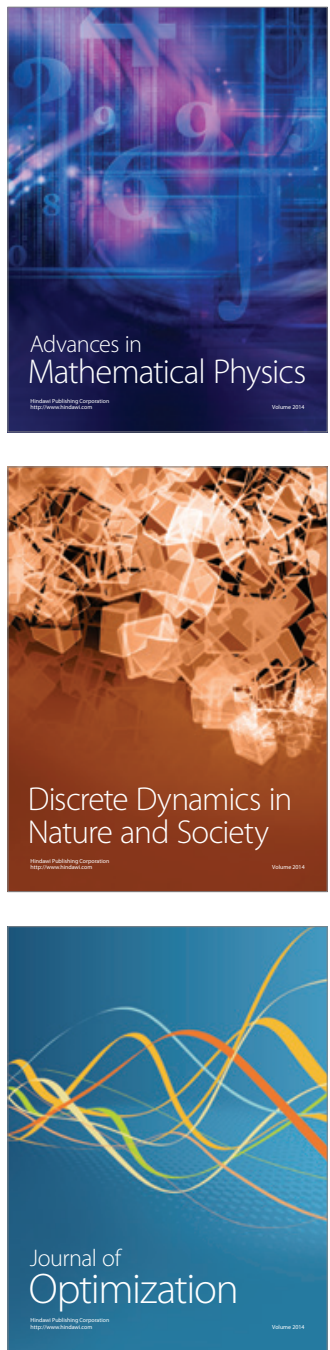